\title{
Solvent Residues in Moon Cake Plastic Packaging Bags
}

\author{
Li Xie ${ }^{1, a^{*}}$, Jiang $\mathrm{Yu}^{1, \mathrm{~b}}$, Wei Zhang ${ }^{1, \mathrm{c}}$ and Lu Ren ${ }^{1, \mathrm{~d}}$ \\ ${ }^{1}$ Faculty of Printing Packaging Engineering and Digital Media Technology, Xi' an University of \\ Technology, Xi' an, China 710048

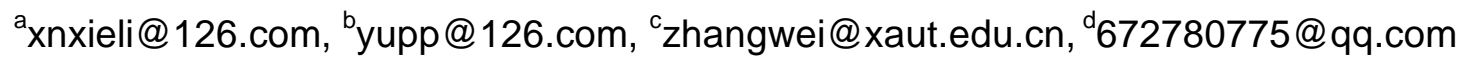 \\ ${ }^{*}$ Corresponding author
}

Keywords: moon cake plastic packaging bag, solvent residue, gas chromatography and mass spectrometry technology.

Abstract. Food packaging plays a crucial role on food safety. A gas chromatography and mass spectrometry technology was used to determine and analyze eight solvent residues in three kinds of moon cake plastic packages. In the experiment, linear calibration curves of the eight compounds were obtained with correlation coefficients of more than 0.9845 , the detection limits were in the range of $0.002-0.009 \mathrm{mg} / \mathrm{m}^{2}$, the recoveries ranged from $85 \%$ to $93 \%$ with RSD less than $3.3 \%$. The results show solvent residues in pastry moon cake plastic packaging bag, vegetarian moon cake plastic packaging bag and flower moon cake plastic packaging bag are respectively $1.489 \mathrm{mg} / \mathrm{m}^{2}, 0.392$ $\mathrm{mg} / \mathrm{m}^{2}, 0.577 \mathrm{mg} / \mathrm{m}^{2}$. Residues of benzenes in the three packages are respectively $0.287 \mathrm{mg} / \mathrm{m}^{2}, 0.201$ $\mathrm{mg} / \mathrm{m}^{2}, 0.194 \mathrm{mg} / \mathrm{m}^{2}$. There are different content of benzenes in plastic films, printing ink and adhesive. The kind and amount of printing ink have a larger impact on solvent residues. Benzenes residues in the three moon cake plastic packaging bags exceed the Chinese national standard.

\section{Introduction}

In addition to food own quality factors, food packaging also plays a crucial role on food safety. Selection and use of food packaging materials inappropriately may cause adverse effect on food safety. Packaging of moon cake in the Mid-autumn festival may bring certain harm to the people who eat it. Moon cake is a high-fat food, compound plastic materials high resistance to oxygen and oil are widely used in its inner packaging. There have monomers residue and low molecular substances dissolution during polymerization process. At the same time, in order to improve the properties in processing and use, stabilizing agent, colorant, lubricant, plasticizer and antistatic agent are joined to plastics in production process [1,2]. Moreover, a certain amount of organic solvents, such as toluene, ethyl acetate, butanone are used in gravure printing and solvent-based dry complex process of plastic flexible packaging materials. According to technological requirements, these solvents should volatilize in the production process. But in actual production, due to various reasons, solvents can not completely volatilize and form solvent residues. Under certain conditions, these organisms can migrate from packaging material into the food inside the package and contaminate food.

Scholars in China and abroad have done some research on harmful compounds in food packaging materials [3-11]. Gas chromatography mass spectrometry technology not only plays an efficient separation ability, but also combines the ability of identify specific mass. With high sensitivity and strong anti-jamming capability, GCMS has been widely used in chemical, biological and environmental analysis. In this paper, GCMS was used to establish experiment. Solvent Residues in three kinds of moon cake packaging bag were detected and analyzed. Valuable references will help to the safety production of moon cake packaging.

\section{Experiment}

\section{Instruments and reagents}

TurboMass Headspace sampler, gas chromatography and mass spectrometry system (Clarus 600, PerkinElmer, USA) were used for experiment. Ethyl acetate, $o$-Xylene, $m / p$-Xylene, isopropyl alcohol, 
benzene, butyl acetate, cyclohexanone and ethyl benzene (purity $>99.5 \%$, Tianjin, China) were prepared. Pastry moon cake plastic packaging bag (BOPP/CPP, printed with yellow ink, magenta ink and cyan ink), vegetarian moon cake plastic packaging bag (BOPP/CPP, printed with magenta ink, cyan ink and blue ink), flower moon cake plastic packaging bag (BOPP/CPP, printed with yellow ink, magenta ink and blue ink), BOPP and CPP before printing, yellow ink, magenta ink, cyan ink and blue ink, adhesive.

\section{Experimental method}

Balance temperature was $85^{\circ} \mathrm{C}$, balance time was $40 \mathrm{~min} .30 \mathrm{~m} \times 0.25 \mathrm{~mm} \times 0.25 \mu \mathrm{m}$ VOC special capillary column. Oven temperature was held at $36{ }^{\circ} \mathrm{C}$ for $4 \mathrm{~min}$, then raised at $12{ }^{\circ} \mathrm{C} / \mathrm{min}$ up to $200{ }^{\circ} \mathrm{C}$; carrier gas, $\mathrm{He}$ (purity $>99.999 \%$ ) at a constant flow rate of $1.5 \mathrm{~mL} / \mathrm{min}$. Interface temperature was 210 ${ }^{\circ} \mathrm{C}$, ion source temperature was $200{ }^{\circ} \mathrm{C}$. Ion source voltage was $70 \mathrm{eV}$.

$5 \mathrm{~cm} \times 10 \mathrm{~cm}$ of moon cake packaging materials were clipped in accordance with location of printing pattern, quickly cut into $0.5 \mathrm{~cm} \times 2.5 \mathrm{~cm}$ strips. Then these strips were sealed in $20 \mathrm{~mL}$ headspace bottles. About $5 \mathrm{mg}$ of printing ink and adhesive were put into headspace bottles respectively. Standard solutions of the eight reagents in methyl alcohol at a series density of standard solution $(0.01 \%, 0.03 \%$, $0.05 \%, 0.07 \%, 0.09 \%, 0.1 \%)$ were obtained. $1 \mu \mathrm{L}$ standard solutions was spiked into headspace bottles to test.

\section{Results and discussion}

\section{Determination of standard solutions}

Fig. 1 shows peak time of isopropyl alcohol, ethyl acetate, benzene, butyl acetate, ethyl benzene, $\mathrm{m} / \mathrm{p}$-xylene, $o$-xylene and cyclohexanone is respectively $1.80 \mathrm{~min}, 2.53 \mathrm{~min}, 3.03 \mathrm{~min}, 6.22 \mathrm{~min}, 6.86$ $\mathrm{min}, 6.99 \mathrm{~min}, 7.30 \mathrm{~min}$ and $7.41 \mathrm{~min}$. Peak area as vertical coordinate, quantity concentration of compound as horizontal coordinate, regression equations of the eight compounds were calculated. The results are shown in Table 1. Linear calibration curves of the eight compounds are obtained with correlation coefficients of more than 0.9845 , detection limits are in the range of $0.002-0.009 \mathrm{mg} / \mathrm{m}^{2}$, recoveries range from $85 \%$ to $93 \%$ with RSD less than $3.3 \%$.

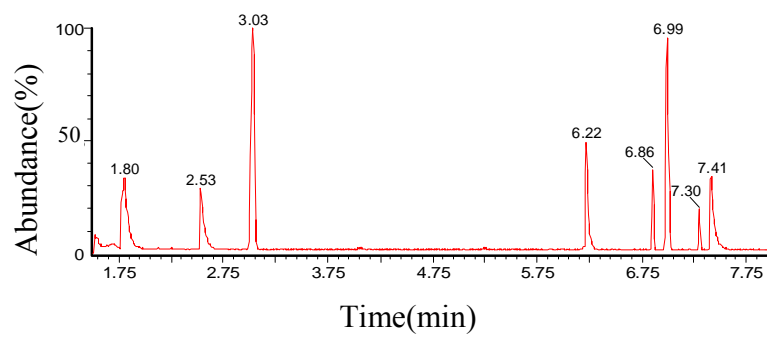

Fig. 1 Chromatogram of standard solution Table 1 Regression equations, correlation coeffic

\begin{tabular}{cccccc}
\hline Compound & Regression equation & $\begin{array}{c}\text { Correlation } \\
\text { coefficient }\end{array}$ & $\begin{array}{c}\text { Detection } \\
\text { limit }\left(\mathrm{mg} / \mathrm{m}^{2}\right)\end{array}$ & $\begin{array}{c}\text { Recovery } \\
(\%)\end{array}$ & RSD $(\%)$ \\
\hline Isopropyl alcohol & $y=236.304 x-5370.6$ & 0.9889 & 0.005 & 89 & 2.5 \\
Ethyl acetate & $y=189.783 x-512.1$ & 0.9923 & 0.002 & 87 & 2.3 \\
Benzene & $y=128.545 x-3681.4$ & 0.9987 & 0.006 & 85 & 2.9 \\
Butyl acetate & $y=63.367 x-276.21$ & 0.9936 & 0.004 & 91 & 2.8 \\
Ethylbenzene & $y=87.632 x-1954.74$ & 0.9899 & 0.007 & 88 & 3.2 \\
$m / p$-Xylene & $y=362.423 x-8563.45$ & 0.9893 & 0.005 & 86 & 3.3 \\
$o$-Xylene & $y=435.874 x-760.52$ & 0.9845 & 0.009 & 89 & 3.1 \\
Cyclohexane & $y=687.23 x-856.4$ & 0.9975 & 0.006 & 93 & 2.6 \\
\hline
\end{tabular}

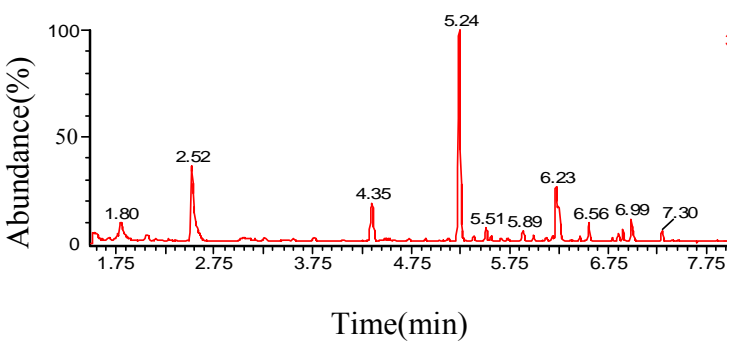

Fig. 2 Chromatogram of pastry moon cake bag 西

.




\section{Solvent residues in moon cake plastic packaging bag and its raw materials}

Chromatograms of three moon cake plastic bags are shown in Fig. 2, Fig. 3 and Fig. 4. Eight compounds were determined by peak time and mass spectrum library, and quantified by the regression equations. The results are shown in Table 2.

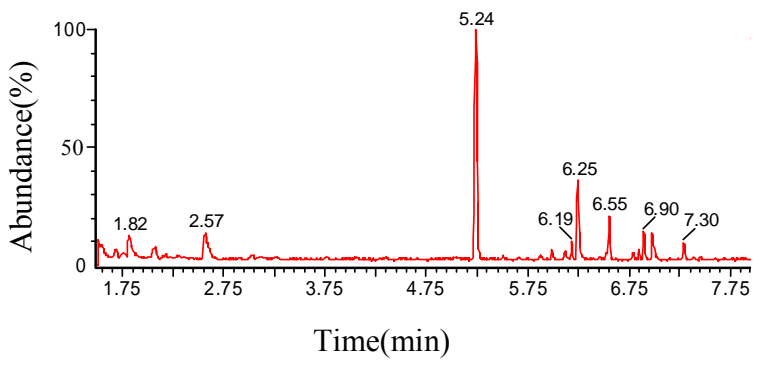

Fig. 3 Chromatogram of vegetarian moon cake bag

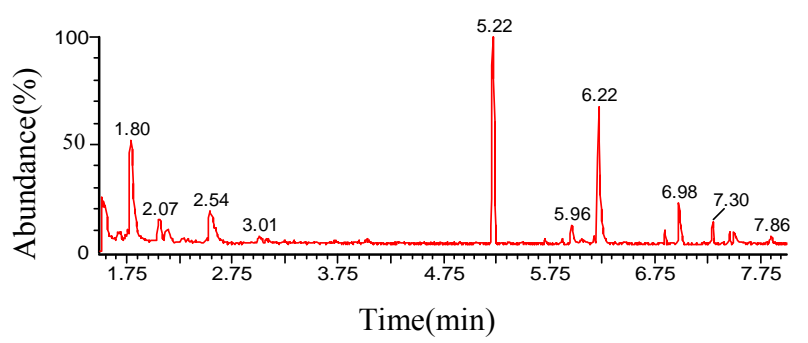

Fig. 4 Chromatogram of flower moon cake bag

Table 2 Solvent residues in the three moon cake plastic bags and raw materials

\begin{tabular}{|c|c|c|c|c|c|c|c|c|c|}
\hline Sample & $\begin{array}{l}\text { Isopropyl } \\
\text { alcohol }\end{array}$ & $\begin{array}{l}\text { Ethyl } \\
\text { acetate }\end{array}$ & Benzene & $\begin{array}{c}\text { Butyl } \\
\text { acetate }\end{array}$ & $\begin{array}{c}\text { Ethyl } \\
\text { benzene }\end{array}$ & $\begin{array}{c}m / p- \\
\text { Xylene }\end{array}$ & $\begin{array}{c}o- \\
\text { Xylene }\end{array}$ & Cyclohexanone & Amount \\
\hline $\begin{array}{c}\text { Pastry } \\
\text { moon cake } \\
\text { bag } \\
\left(\mathrm{mg} / \mathrm{m}^{2}\right)\end{array}$ & 0.064 & 0.796 & 0.012 & 0.342 & 0.060 & 0.067 & 0.148 & - & 1.489 \\
\hline $\begin{array}{c}\text { Vegetarian } \\
\text { moon cake } \\
\text { bag } \\
\left(\mathrm{mg} / \mathrm{m}^{2}\right)\end{array}$ & 0.042 & 0.146 & 0.011 & 0.003 & 0.041 & 0.046 & 0.103 & - & 0.392 \\
\hline $\begin{array}{c}\text { Flower } \\
\text { moon cake } \\
\text { bag } \\
\left(\mathrm{mg} / \mathrm{m}^{2}\right)\end{array}$ & 0.058 & 0.136 & 0.010 & 0.189 & 0.041 & 0.047 & 0.096 & - & 0.577 \\
\hline $\begin{array}{l}\text { BOPP ( } \\
\left.\mathrm{mg} / \mathrm{m}^{2}\right)\end{array}$ & 0.042 & 0.019 & 0.007 & 0.002 & 0.031 & 0.032 & 0.066 & - & 0.199 \\
\hline $\begin{array}{c}\mathrm{CPP}( \\
\left.\mathrm{mg} / \mathrm{m}^{2}\right)\end{array}$ & 0.042 & 0.016 & 0.007 & 0.002 & 0.020 & 0.022 & 0.028 & - & 0.137 \\
\hline $\begin{array}{c}\text { Yellow ink } \\
(\mathrm{mg} / \mathrm{kg})\end{array}$ & 74.946 & $\begin{array}{c}1741.8 \\
8\end{array}$ & 34.368 & 36.783 & 41.323 & 34.961 & 74.364 & - & 2038.625 \\
\hline $\begin{array}{l}\text { Magenta } \\
\text { ink } \\
(\mathrm{mg} / \mathrm{kg})\end{array}$ & 142.34 & 441.24 & 3.084 & 8.957 & 0.087 & 206.94 & 0.069 & 2523.4 & 3326.117 \\
\hline $\begin{array}{l}\text { Cyan ink } \\
(\mathrm{mg} / \mathrm{kg})\end{array}$ & 46.823 & 0.187 & 91.99 & 2.132 & 0.268 & 356.44 & 1351.8 & - & 1849.64 \\
\hline $\begin{array}{l}\text { Blue ink } \\
(\mathrm{mg} / \mathrm{kg})\end{array}$ & 115.23 & 0.078 & 0.539 & 7.391 & 557.43 & 187.12 & 1831.8 & 152.2 & 2851.788 \\
\hline $\begin{array}{c}\text { Adhesive } \\
(\mathrm{mg} / \mathrm{kg})\end{array}$ & 3.303 & 0.029 & 0.016 & 0.112 & 0.533 & 0.694 & 0.870 & - & 5.557 \\
\hline
\end{tabular}

- : No detected

\section{Analysis of Solvent residues in moon cake plastic packaging bag}

Table 2 shows solvent residues in pastry moon cake plastic bag, vegetarian moon cake plastic bag and flower moon cake plastic bag are respectively $1.489 \mathrm{mg} / \mathrm{m}^{2}, 0.392 \mathrm{mg} / \mathrm{m}^{2}$ and $0.577 \mathrm{mg} / \mathrm{m}^{2}$. Benzenes in the three packages are respectively $0.287 \mathrm{mg} / \mathrm{m}^{2}, 0.201 \mathrm{mg} / \mathrm{m}^{2}$ and $0.194 \mathrm{mg} / \mathrm{m}^{2}$. There is high content of xylene and isopropyl alcohol in BOPP and CPP. There is more ethyl acetate in yellow ink. 
There is more cyclohexanone in magenta ink. There is high content of xylene in cyan ink and blue ink. Thus, type and amount of printing ink for packaging have a greater influence on the organic solvent residues. Benzenes residues in the three moon cake plastic packaging bags exceed the Chinese national standard.

\section{Ways of reducing solvent residues in moon cake plastic packaging bag}

Benzenes exist in plastic raw materials, printing ink and adhesive. So, reducing solvent residues in moon cake plastic bags primary carries out from selecting raw materials and improving production process.

Strengthen supervision and avoid use of waste plastic. Prevent benzenes solvent residues exceeding standard caused by free monomer in plastics. Select materials according to their character, for example, affinity of toluene to BOPP is better than other materials, thus, toluene easy to remain on the printed material.

Minimize the use of ink when design of packaging decoration. Avoid large areas of solid print and overprint which easy to cause ink layer thicker and solvents evaporate less. Use environment friendly ink and adhesive as far as possible. In order to reduce organic solvents in printing ink, fast evaporating organic solvent of non-benzenes ink and water-based ink should be used in printing process. At the same time, use solvent-free composite adhesive.

Improve parameters in production process. Progressively increase the drying temperature and air flowing rate during printing. At the same time, reduce humidity of the environment in order to promote organic solvent evaporating rapidly.

Use flexography printing technology instead of gravure printing. Although quality of flexography printing is slightly lower, its ink usage is less and ink layer is thin which benefit to environment protection.

\section{Conclusions}

A gas chromatography and mass spectrometry technology was used to determine and analyze eight solvent residues in three kinds of moon cake plastic packages. Effective methods to reduce benzenes solvent residues in moon cake bags have been analyzed.

\section{Acknowledgment}

This research was financially supported by the Foundation of Xi' an science and technology plan project, China (Project No. CXY1433(7)).

\section{References}

[1] Y. Zhu, Z.W. Wang, Packaging Engineering, 27 (2006) 40-41.

[2] Y.W. Liao, G.R. Cao, W.C. Xu, Packaging Engineering, 29 (2008) 228-231.

[3] S.H. Zhou, Q.B. Lin, B. Li, Packaging and Food Machinery, 33 (2015) 56-62.

[4] Y.N. Jiao, L. Ding, J.Y. Xiao, Journal of Food Safety and Quality, 4 (2013) 981-987.

[5] M. Aznar, C. Domeno, C. Nerin, Dyes and Pigments, 114 (2015) 85-92.

[6] J. Muncke, Encyclopedia of Food Safety, 2 (2014) 430-437.

[7] J.J. Zhu, J.E. Hill, Food Microbiology, 34 (2013) 412-417.

[8] P. Trefz, S. Kischkel, D. Hein, Journal of Chromatography A, 1219 (2012) 29-38.

[9] F. Biasioli, C. Yeretzian, F. Gaseri, Trends in Analytical Chemistry, 30 (2011) 968-977.

[10] L. Xie, J. Yu, P.G. Ren, Chinese Journal of Analytical Chemistry, 39 (2011) 1368-1372. 
[11] L. Xie, D.P. Jia, J.H. Ci, Packaging Engineering, 35 (2014) 34-37. 